Journal of Environmental Sciences (JES)

Faculty of Graduate Studies and Environmental Research, Ain Shams University

Osman, et al.

\title{
EFFICACY AND SAFETY OF SUBLINGUAL IMMUNOTHERAPY IN ALLERGIC ASTHMA AMONG CHILDREN AND ADOLESCENTS INTERVENTIONAL STUDY
}

\author{
Mohamed E. Osman ${ }^{(1)}$; Mahmoud S. El Bokhary ${ }^{(2)}$ \\ and Hewaida M. Kamal ${ }^{(3)}$
}

1) Clinical Hematology Department, New Cairo Police Hospital 2) Department of Environmental Medical Science, Institute of Environment Studies and Research, Ain Shams University 3) Department of Clinical and Chemical Pathology,Faculty of Medicine, Banha University.

\begin{abstract}
Background: bronchial asthma is a chronic inflammatory disorder with bronchial hyper-responsiveness. Environmental exposure in sensitized individuals is a major inducer of Allergy-associated asthma in children and adults, sublingual immunotherapy (SLIT) leads to improvement in their pulmonary functions and asthma control.

Objectives: To Evaluate the Efficacy and Safety of Sublingual Immunotherapy in Allergic Asthma among Children and Adolescents.

Methods: A 12 months prospective, open, low Interventional, Randomized, Controlled, single-site Study (Egyptian company for production of vaccines, sera and drugs VACSERA, allergy, and immunology clinic) was conducted between March 29, 2016, and December 27, 2018. Four groups including 62 allergic asthmatics patients both children $(\mathrm{n}=30)$, and adults $(\mathrm{n}=32)$, evaluating SLIT for a single-allergen (i.e. house dust mite) for 12 months, Adults received either SLIT with the pharmacotherapy $(n=17)$, or pharmacotherapy alone $(n=15)$. Children received either SLIT with the pharmacotherapy $(n=14)$, or pharmacotherapy alone $(n=16)$. Physiological parameters (Spirometry), Asthma control Questionnaires, A complete blood
\end{abstract}

Vol.(50); Iss.(8); No.(5); Aug. 2021

197

ISSN 1110-0826

Online ISSN 2636-3178 
picture including peripheral blood Eosinophilic count, and the environmental preventive therapy were done to all patients.

Results: After 1-year treatment of patients treated with SLIT and pharmacotherapy, were compared with those who received pharmacotherapy alone. There was a significant improvement in asthma control score, a significant increase in actual FEV1, FVC in SLIT with the pharmacotherapy groups in adults and children when compared with pharmacotherapy alone. There was a significant decrease in the eosinophilic count when compared with patients treated with the pharmacotherapy alone. There is a significant difference between children and adults regarding the occurrence of adverse effects in the form of Local reaction not requiring treatment (mouth, throat, and skin; irritation/swelling/pain) reported in SLIT with the pharmacotherapy groups.

Conclusion: patients treated with SLIT demonstrated clinical improvement compared with those who received pharmacotherapy in adult asthmatics and children sensitized to HDM.

Keywords: asthma, sublingual, immunotherapy.

\section{INTRODUCTION}

According to the Global Initiative for Asthma, bronchial asthma is a chronic inflammatory disorder that is related to hyper responsiveness of the airways and leads to repeated episodes of wheezing, dyspnea, chest tightness, and cough, particularly at night or early in the morning. These episodes are usually associated with extensive but variable bronchial obstruction, which is often reversible, either spontaneously or after treatment (GINA. 2012).

Asthma represents one of the most commons chronic diseases and is a major public health problem worldwide (GINA. 2012). 
Journal of Environmental Sciences (JES)

Faculty of Graduate Studies and Environmental Research, Ain Shams University

Osman, et al.

In the majority of patients control of asthma as defined by guidelines can be achieved with long-term maintenance medications (Brehm JM, et al., 2009).

However, a substantial proportion of patients do not achieve optimal asthma control despite even high dose treatment. In particular, inadequately controlled patients with severe persistent asthma are at high risk of severe exacerbations and asthma-related mortality. These patients represent the greatest unmet medical need among the asthmatic population today (Freishtat RJ, et al., 2010).

One in 11 children and 1 in 12 adults have asthma, and this disease resulted in 10.5 million missed school days and 14.2 million missed work days in 2008. The United States spends \$56 billion annually on asthma medications (Freishtat RJ, et al., 2010).

Asthma is a common chronic illness that affects approximately 9\% of African- American adults (CDC. 2013).

The prevalence of asthma in the U.S. population is $9 \%$, and $62 \%$ of these individuals have "allergic" asthma (i.e., show evidence for atopy) (Lin SY.et al., 2013).

Among childhood asthmatics in Egypt, Madkour et al reported that the overall prevalence of childhood asthma in Egypt was $12 \%$ in schoolchildren (Madkour M, El Bokhary MS, Kamal HM et al., 2014). 
Allergic diseases mostly begin in early childhood, but they can also manifest in the later stages of life. Environmental factors are mentioned as the most important risk factors, primarily air pollution (Zvezdin B.et al., 2011).

In patients with allergic asthma, the same allergens that trigger allergies (e.g., pollen, dust mites) can also induce asthma symptoms and exacerbations. There are three treatment options for patients with allergic asthma: 1) allergen avoidance, 2) pharmacotherapy (e.g., inhaled corticosteroids), and 3) immunotherapy (Lin SY.et al., 2013).

Despite available effective treatments, many patients with asthma do not have their condition under control—a problem that disproportionately affects racial and ethnic minorities. Allergen-specific immunotherapy (IT) is recommended for patients whose allergic asthma cannot be adequately controlled by allergen avoidance and medication (Jutel M. et al., 2014).

However, studies suggest that the clinical benefits of IT and its potential to reduce asthma symptoms long-term may justify even broader use to improve asthma outcomes (Jutel M. et al., 2014).

There are two main forms of IT: subcutaneous IT (i.e., allergy shots) and sublingual IT (i.e., allergen placement under the tongue). In 2013, the Agency for Healthcare Research and Quality (AHRQ) published an Overall, highquality evidence is strong that both subcutaneous and sublingual IT are effective and safe for the treatment of asthma, although there is insufficient evidence to favor one form of IT over another. The magnitude of the effect is 
hard to judge because the systematic review reported effects qualitatively rather than as changes in symptom scores (Lin SY.et al., 2013).

Unlike pharmacotherapy, immunotherapy targets the immunologic cause of respiratory symptoms and is the only treatment that alters the course of respiratory allergic disease (AAAAI. 2014).

However, the inconvenience of injections may make some patients reluctant to undergo this form of treatment. Studies have found that factors related to both inconvenience and safety contribute to premature discontinuation of subcutaneous immunotherapy (AAAAI. 2014).

There is increasing interest in sublingual forms of IT as an alternative treatment to subcutaneous IT due to more convenient administration (does not require injections or office visits), which potentially improved safety (reduced risk of anaphylaxis), and shorter time to achieve the effect. Also, despite its broad use in Europe, Asian, and Latin America, sublingual IT in the US was only recently approved by the FDA(Jutel M. et al., 2014).

In May 2014, the FDA approved the first three allergen tablets for sublingual administration (two are for grass pollens and one is for ragweed). However, even before the FDA approval, U.S. physicians had been increasingly prescribing sublingual IT "off-label" (i.e., they prescribe FDAapproved allergen extracts for oral use instead of their labeled use for injections). AHRQ and the American Academy of Allergy, Asthma, and Immunology (AAAAI) have both called for head-to-head trials comparing 
Journal of Environmental Sciences (JES)

Faculty of Graduate Studies and Environmental Research, Ain Shams University

Osman. et al.

subcutaneous and sublingual IT for the treatment of asthma (Romana $\mathrm{H}$, et al., 2014).

However, experience among Egyptian asthmatics is still lacking. So, in the present study the role of Sublingual Immunotherapy in Allergic Asthma among Children and Adolescents Egyptian asthmatics will be evaluated.

The current interventional study aims to evaluate the efficacy and safety of sublingual immunotherapy in allergic asthma among children and adolescents.

\section{MATERIALS AND METHODS}

The study was conducted between March 29, 2016, and September 27, 2019, in a prospective, open, interventional, randomized, controlled, singlesite Study (Egyptian company for production of vaccines, sera and drugs VACSERA, allergy, and immunology clinic) The study included 62 allergic asthmatics patients both children and adults, evaluating a single-allergen Immunotherapy AIT (i.e. house dust mite Sublingual Immunotherapy SLIT), for 12 months of AIT treatment.

Thirty two adults and 30 children, with mite-induced allergic asthma with symptomatic, physician confirmed asthma were studied by Skin prick testing which was conducted to Dermatophagoides pteronyssinus (D.pt) and/or Dermatophagoides farinae (D.f.), by The house dust material ( a 10:10:1 mixture of Dermatophagoides pteronyssinus whole bodies, Dermatophagoides farinae whole bodies, and feces from both species, which 
Journal of Environmental Sciences (JES)

Faculty of Graduate Studies and Environmental Research, Ain Shams University

Osman, et al.

reflects the composition of mite material during natural exposure) . In combination with a history of asthma symptoms due to allergen exposure, Patients were recruited during the screening period the period from March 2016 to December 2017 from (Egyptian company for production of vaccines, sera and drugs VACSERA, allergy, and immunology clinic).

Skin prick testing visits occurred during the screening period. Where patients were randomized to one of the four groups 2 groups, $3 r$ HDMinduced Allergic Asthmatics Adults (G1, n.17) and children (Gr, n.15) with (ICS+LABA with Sublingual Immunotherapy [SLIT] Sublingual aqueous (held under tongue x 2 minutes then swallowed), and pharmacotherapy ICS+LABA, group one and three were compared to 2groups, 30 HDMinduced Allergic Asthmatics Adults $\left(\mathrm{G}^{\mathrm{r}}, \mathrm{n} .15\right)$ and children $(\mathrm{G} 4, \mathrm{n} .15)$ with pharmacotherapy only (positive control) without Sublingual Immunotherapy and were followed-up prospectively for 1 year.

During the 12 months of the study, subjects were requested to fill out monthly Questionnaires concerning compliance with study medication, the occurrence of acute exacerbations, and the use of concomitant medication. Standardized self-administered asthma control assessment tools included the Asthma Control Test (ACT) (Yahya A Alzahrani, Ellen A Becker, et al., 2016), at baseline and 12 months of treatment of each patient. This study was conducted in compliance with Good Clinical Practice guidelines and the Declaration of Helsinki (WMA. 2004). The study protocol was approved by 
Journal of Environmental Sciences (JES)

Faculty of Graduate Studies and Environmental Research, Ain Shams University

Osman. et al.

the Medical Environmental Sciences Department, Institute of Environment Studies and Research, Ain Shams University. All study subjects were recruited voluntarily and after Discussion with the patients as regards the benefits and hazards of the study and a written informed consent was obtained from the adult participants, children guardians, and their caregivers. The study objectives and tools were explained to the participants and their caregivers, and they were reassured about the confidentiality of the study data. Inclusion Criteria: included allergic asthma, adherence with therapy patients had to have skin test positivity to D.pt and/or D.f., Subjects eligible for inclusion in the trial were male and female adult (aged 18 and above till 65 years) and children (aged 18 years and below) (WHO aging classification.2019), with HDM-induced allergic asthma of 1 year or longer in duration. Subjects were required to have an Asthma Control Test (ACT) of 19 points and below (Melosini L, et al., 2012); a positive skin prick test response (wheal diameter >_3 mm larger than saline control) to D pteronyssinus, D farinae, or both at screening; and an FEV1 of $70 \%$ of predicted value or greater at screening, recruitment, and randomization. Exclusion criteria included (1) incorrect diagnosis(2) non-allergic asthma(3) non-adherence with therapy(4) Patients with chronic bronchitis, emphysema, and peripheral airway diseases, systemic immunological disorders, the severe atopic dermatitis, severe asthma with forced expiratory volume in $1 \mathrm{~s}$ (FEV1) Less than $70 \%$,asthma requiring medium- or high-dose inhaled corticosteroids within the last 12 months before screening, previous use of allergen 204 Vol.(50); Iss.(8); No.(5); Aug. 2021

ISSN 1110-0826

Online ISSN 2636-3178 
Journal of Environmental Sciences (JES)

Faculty of Graduate Studies and Environmental Research, Ain Shams University

Osman, et al.

immunotherapy or HDM immunotherapy within the past 3 years. The following parameters will be performed to the four groups (1) full history and physical examination (2) Skin prick test Using HDM: House dust mite extract (also for immunotherapy) skin prick method was done using House dust mite extracts. skin prick test greater than $3 \mathrm{~mm}$ (wheal) wheal cutoff for a positive test result provided $100 \%$ sensitivity and $100 \%$ negative predictive value. We used HDM: House dust mite allergen extracts which were prepared from The house dust material was a 10:10:1 mixture of Dermatophagoides pteronyssinus whole bodies, Dermatophagoides farinae whole bodies, and feces from both species, which reflects the composition of mite material during natural exposure (3) Asthma Control Test (ACT) (4) Spirometry (FEV1, FVC, FEV1/FVC) spirometry is measured, The patient must be clinically stable, should sit straight, with head erect, nose clip in place, and holding the mouthpiece tightly between the lips.

Initially, he or she should breathe in and out at the tidal volume (V T: normal quiet breathing) to record the tidal flow-volume loop. Then, when the patient is ready, the technician instructs him/her to inhale maximally to TLC, and then exhale as fast and as completely as possible to record the FVC. The point at which no more air can be exhaled is the RV. This test is then repeated 3 times and takes the best reading. Treatment and Immunotherapy Technique: The standardized extract used throughout the study was a 1: 1 mixture of D.pt and D.f administered as a glycerinated solution (SLITs; SDV, Ontario, 
Canada). The first doses were administered on-site, and subjects were monitored for 30 minutes after the SLIT intake. Subsequent doses were selfadministered at home. The SLIT was to be placed under the tongue and allowed to remain for a few seconds until dissolved. Subjects were advised to take the drops early in the morning before breakfast, not to swallow during the first minute after administration, and held under the tongue for $2 \mathrm{~min}$ before swallowing. The SLIT was self-administered at home and included a 1-month induction phase (Build-up phase) followed by a maintenance phase of five drops three times a week for 11 months .

\section{RESULTS}

Table (1) Comparison between the studied adult patients groups regarding asthma control test before and after therapy:

\begin{tabular}{||c|c|c|c|c||}
\hline $\begin{array}{c}\text { ASTHMA } \\
\text { CONTROL } \\
\text { TEST } \\
\text { POINTS }\end{array}$ & $\begin{array}{c}\text { ADULT WITH } \\
\text { SLIT (N=17) }\end{array}$ & $\begin{array}{c}\text { ADULT } \\
\text { WITHOUT SLIT } \\
\text { (N=15) }\end{array}$ & \multicolumn{2}{||}{ TEST } \\
\cline { 2 - 5 } & Mean \pm SD & Mean \pm SD & t & p \\
\hline \hline Before & $21 \pm 4$ & $22 \pm 3.8$ & 0.722 & 0.476 \\
\hline After & $28 \pm 4$ & $22 \pm 4$ & 4.23 & $<0.001^{* *}$ \\
\hline P(paired t) & $<0.001^{* *}$ & $>0.999$ & & \\
\hline \% change & $33.3 \%$ & $0 \%$ & & \\
\hline
\end{tabular}

t Independent sample t-test $\mathrm{p}>0.05$ is statistically non-significant

$* * p \leq 0.001$ is statistically highly significant

There is a statistically non-significant difference between the studied groups regarding the level of asthma control before intervention. However, 
there is a significant difference between them after the intervention. There is a significant improvement in the level of asthma control in the adult with slit group after the intervention, on the other hand; there is a non-significant change in it among the control group (percent increase in mean level was $33.3 \%$ for the intervention group and $0 \%$ for the control group).

Table (2): Comparison between the studied adult patients groups regarding predicted FEV1 before and after therapy:

\begin{tabular}{||c|c|c|c|c||}
\hline \multirow{2}{*}{$\begin{array}{c}\text { PREDICTED } \\
\text { FEV1 }\end{array}$} & $\begin{array}{c}\text { ADULT WITH } \\
\text { SLIT (N=17) }\end{array}$ & $\begin{array}{c}\text { ADULT } \\
\text { WITHOUT } \\
\text { SLIT(N=15) }\end{array}$ & \multicolumn{2}{||}{ TEST } \\
\cline { 2 - 5 } & Mean + SD & Mean \pm SD & t & p \\
\hline \hline Before & $73 \pm 6.58$ & $74 \pm 5.18$ & -0.473 & 0.637 \\
\hline After & $105 \pm 0.20$ & $79 \pm 0.30$ & 190.69 & $<0.001^{* *}$ \\
\hline P (paired t) & $<0.001 * *$ & $<0.5$ & & \\
\hline \% change & $43.84 \%$ & $1.92 \%$ & & \\
\hline
\end{tabular}

There is a statistically non-significant difference between the studied groups regarding predicted FEV1 before the intervention. However, there is a significant difference between them after the intervention. There is a significant increase in predicted FEV1 in adult with slit group after the intervention, on the other hand; there is a non-significant change in it among the control group after the intervention. The percent increase in mean predicted FEV1 was $43.84 \%$ for the intervention group and $1.92 \%$ for the control group). 
Table (3): Comparison between the studied children patients groups regarding asthma control test before and after therapy:

\begin{tabular}{||c|c|c|c|c||}
\hline \hline \multirow{2}{*}{$\begin{array}{c}\text { ASTHMA } \\
\text { CONTROL }\end{array}$} & $\begin{array}{c}\text { CHILDREN } \\
\text { WITH SLIT } \\
\text { (N=14) }\end{array}$ & $\begin{array}{c}\text { CHILDREN } \\
\text { WITHOUT SLIT } \\
\text { (N=16) }\end{array}$ & \multicolumn{2}{|c||}{ TEST } \\
\cline { 2 - 5 } & Mean \pm SD & Mean \pm SD & t & p \\
\hline \hline Before & $20.76 \pm 4.4$ & $20.96 \pm 4.1$ & -0.192 & 0.898 \\
\hline After & $27 \pm 4$ & $20.76 \pm 4.1$ & 4.206 & $<0.001 * *$ \\
\hline P (paired t) & $0.001 * *$ & 0.891 & & \\
\hline \% change & $30.06 \%$ & $-0.95 \%$ & & \\
\hline
\end{tabular}

There is a statistically non-significant difference between the studied groups regarding the level of asthma control before intervention. However, there is a significant difference between them after the intervention. There is a significant improvement in the level of asthma control in the children with slit group after the intervention, on the other hand; there is a non-significant change in it among the control group (percent increase in mean level was $30.06 \%$ for intervention group; however, the level decreased by $0.95 \%$ for the control group).

Table (4): Comparison between the studied children patients groups regarding predicted FEV1 before and after therapy:

\begin{tabular}{||c|c|c|c|c||}
\hline \hline $\begin{array}{c}\text { PREDICTED } \\
\text { FEV1 }\end{array}$ & $\begin{array}{c}\text { CHILDREN } \\
\text { WITH SLIT } \\
\text { (N=14) }\end{array}$ & $\begin{array}{c}\text { CHILDREN } \\
\text { WITHOUT SLIT } \\
\text { (N=16) }\end{array}$ & \multicolumn{2}{||}{ TEST } \\
\cline { 2 - 5 } & Mean \pm SD & Mean \pm SD & t & p \\
\hline \hline Before & $71 \pm 7.6$ & $70.1 \pm 7.6$ & 0.324 & 0.749 \\
\hline After & $104 \pm 0.20$ & $78 \pm 0.30$ & 243.19 & $<0.001^{* *}$ \\
\hline P (paired t) & $<0.001 * *$ & $<0.5$ & & \\
\hline \% change & $46.48 \%$ & $5.69 \%$ & & \\
\hline
\end{tabular}


There is a statistically non-significant difference between the studied groups regarding predicted FEV1 before the intervention. However, there is a significant difference between them after the intervention. There is a significant increase in predicted FEV1 in children with slit group after the intervention, on the other hand; there is a non-significant change in it among the control group after the intervention. The percent increase in mean predicted FEV1 was $46.47 \%$ for the intervention group and $5.69 \%$ for the control group).

Table (5): Comparison between the studied patients regarding the occurrence of adverse events:

\begin{tabular}{||c|c|c||}
\hline \multirow{2}{*}{ ADVERSE EVENTS } & WITH SLIT & WITHOUT SLIT \\
\cline { 2 - 3 } & Mean \pm SD & Mean \pm SD \\
\hline Adult & $0.0^{\circ \wedge} \pm 0.018$ & 0 \\
\hline Children & $0.21 \pm 0.18$ & 0 \\
\hline $\mathrm{P}(\mathrm{t})$ & $0.002^{*}$ & \\
\hline
\end{tabular}

There is a significant difference between children and adult regarding the occurrence of adverse effects in the form of Local reaction not requiring treatment (mouth, throat, and skin; irritation/swelling/pain).

\section{DISCUSSION}

A 12 months prospective, open, low Interventional, Randomized, Controlled, single-site Study (Egyptian company for production of vaccines, sera, and drugs VACSERA, allergy, and immunology clinic) conducted between March 29, 2016, and September 27, 2019. The Efficacy and Safety 
Journal of Environmental Sciences (JES)

Faculty of Graduate Studies and Environmental Research, Ain Shams University

Osman. et al.

of Sublingual Immunotherapy in Allergic Asthma among Children and Adolescents were evaluated 30 children (17 girls) 12-18 years of age, 32 adults (16 female) 22-59 years of age suffering from mild to moderate persistent asthma, having HDM-related asthma symptoms, Adults and children were included Our findings concluded that [SLIT] with the pharmacotherapy and the environmental preventive therapy resulted in significant effective improvement in the Asthma control score. There is a significant improvement in the level of asthma control in children with slit group after the intervention, on the other hand; there is a non-significant change in it among the control group (percent increase in mean level was $30.06 \%$ for intervention group; however, the level decreased by $0.95 \%$ for the control group). It is interesting to note, that the review by Compalati et al. (Canonica GW, Compalati E., et al., 2015). Which looked only at HDM -AIT shows significant increase in Asthma control score for asthma. There is a significant improvement in the level of asthma control in an adult with slit group after the intervention, on the other hand; there is a non-significant change in it among the control group (percent increase in mean level was $33.3 \%$ for the intervention group and $0 \%$ for the control group),seven studies had reported on general asthma control, combining asthmatic symptoms, need for symptom relief medication, respiratory function test, and lung hyperreactivity, and found significant improvement for AIT over placebo (F Asamoah, et al., 2017). 
Journal of Environmental Sciences (JES)

Faculty of Graduate Studies and Environmental Research, Ain Shams University

Osman, et al.

\section{CONCLUSION}

Investigating the effectiveness and safety of SLIT for allergic asthma, SLIT with the pharmacotherapy and the environmental preventive therapy showed that SLIT improves asthma control scores and improve lung functions; Local allergic reactions to SLIT are more common in children but infrequently required changes in treatment. Life-threatening events (such as anaphylaxis) are reported rarely .The Study suggest that there is a clinical benefits of SLIT and its potential to reduce asthma symptoms long-term may justify even broader use to improve asthma outcomes, Great potential to improve allergic asthma medication and symptom scores, reduces long-term control medication use, improves the disease-specific quality of life, and may reduce the need for quick-relief medication. SLIT had a favorable safety profile when compared to SCIT, particularly concerning the risk of systemic reactions.

\section{REFERENCES}

AAAAI .SLIT Treatment (Allergy Tablets) for Allergic Rhinitis Nothing to Sneeze About(2014)..http://www.aaaai.org/conditions-andtreatments/library/allergy-library/sublingual-immunotherapy-forallergic-rhinitis.aspx Accessed: Thursday, April 16, 2015.

Brehm ,J.M, Celedon ,J.C, Soto-Quiros ,M.E, Avila L, Hunninghake ,G.M, Forno E, Laskey D, Sylvia ,J.S, Hollis ,B.W, Weiss ,S.T ;and Litonjua AA: Serum vitamin D levels and markers of severity of childhood asthma in Costa Rica. Am J Respir Crit Care Med

Vol.(50); Iss.(8); No.(5); Aug. 2021 
2009, 179:765- 771. http://www.ncbi.nlm.nih.gov/pubmed/ 19179486.

CDC, National Center for Environmental Health: Division of Environmental Hazards and Health Effects (2013) Asthma's Impact on the Nation: Data from the CDC National Asthma Control Program. Available:

http://www.cdc.gov/mmwr/preview/mmwrhtml/mm5140a1.htm. Accessed 1 April 2015.

Freishtat ,R.J, Iqbal ,S.F, Pillai ,D.K, Klein ,C.J, Ryan ,L.M, Benton ,A.S ; and Teach SJ: High prevalence of vitamin D deficiency among inner-city African American youth with asthma in Washington, DC. J Pediatr 2010, 156:948-952. http://ac.els-cdn.com/ S0022347609012906/1-s2.0-S0022347609012906-main.

Global Initiative for Asthma: GINA Report, Global Strategy for Asthma Management and Prevention - Global Initiative for Asthma (GINA). 2012. Available from http://www.ginasthma.org/documents/4. Accessed August 29, 2016

http://effectivehealthcare.ahrq.gov/ehc/products/270/1427/allergy-asthma immunotherapy-130802.pdf Accessed: Thursday, April 16, 2015.

Jutel M. Allergen-specific immunotherapy in asthma. Currnt Treat Options Allergy (2014) 1:213-9. doi:10.1007/s40521-014-0013-1

Lin SY. Allergen-Specific Immunotherapy for the Treatment of Allergic Rhinoconjunctivitis and/or Asthma: Comparative Effectiveness Review. AHRQ Publication No. 13-EHC061-EF 2013.

Madkour M, El Bokhary ,M.S ;and Kamal HM. Environmental Risk Factors For Childhood Asthma Interventional Effect Of Eradicating Indoor Allergens Institute Of Environmental Studies\&Research Ain Shams University; 2014. 
Melosini L, Dente ,F.L, Bacci E, Bartoli ,M.L;and Cianchetti S.Asthmacontro 1 test (ACT): comparison with clinical, functional, and biological markers of asthma control. J Asthma 2012;49(3):317-323.

More ,D.R, Hagan ,L.L. Factors affecting compliance with allergen immunotherapy at a military medical center. Ann Allergy Asthma Immunol 2002, 88(4):391-394 .

Rhodes ,B.J. Patient dropouts before completion of optimal dose, multiple allergen immunotherapy. Ann Allergy Asthma Immunol 1999, 82(3):281-286.

Rhodes ,L. Asthma prevalence and control character-ristics by race/ ethnicity: United States, 2002. Morbid Mortal Wkl Rep 2004; 53:145-8.

Romana ,H. ynia ,W ; and Katie Lewis: Research Prioritization Topic Brief: Immunotherapy Options for the Treatment of Asthma PCORI's ongoing research programs2014 Accessed http://www. pcori.org /conditions-and-treatments/library/allergy-library/sublingualimmunotherapy-for-allergic-rhinitis.aspx on Thursday, April 16, 2018 .

World Health Organization. Definition of an older or elderly person". Who.int. Retrieved 2016-04-04. Accessed 3 Sept 2018.

World Medical Association. Declaration of Helsinki [Web Page] 2004. Available at http://www.wma.net/e/policy/b3.htm Accessed 3 Sept 2018.

Yahya ,A Alzahrani ; and Ellen A Becker; Asthma Control Assessment Tools respire-tory Care January 2016, 61 (1) 106-116; DOI: https://doi.org/10.4187/respcare.04341.

Zvezdin B, Milutinov S, Tanasković I, Kojičić M, Kolarov V, Hromiš S, ; and Ilić $M$. The frequency of sensitization to inhalatory allergens and concomitant rhinitis in asthmatic patients. Vojnosanit Pregl 2011; 68:309-13. 


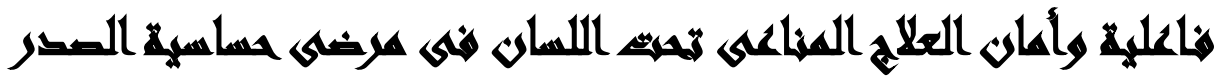

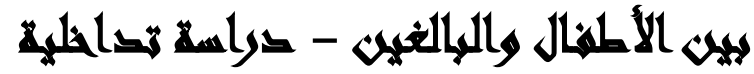

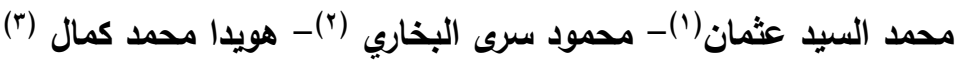

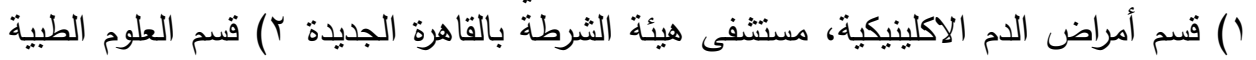

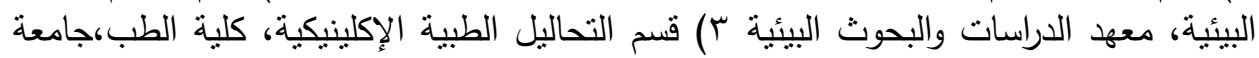

\section{المسرتطلي}

الأشخاص الذين يعانون من الحساسية معرضين أكثر للإصابة بالربو .يقدر أن \% 80 من

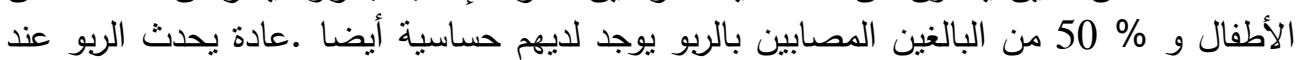

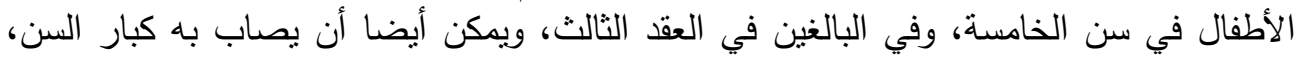

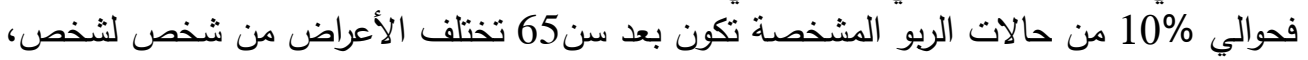

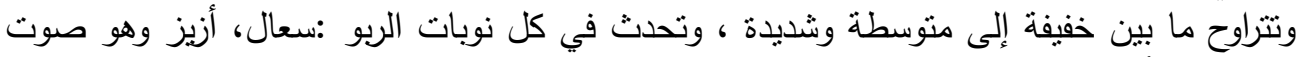

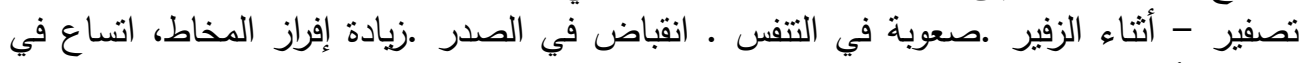

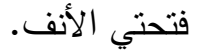

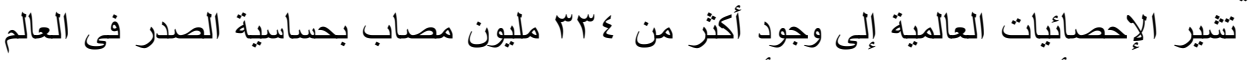

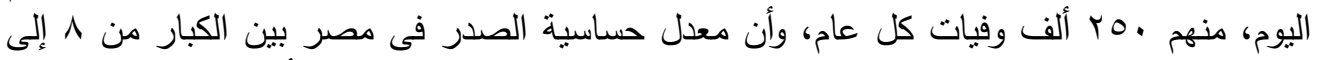

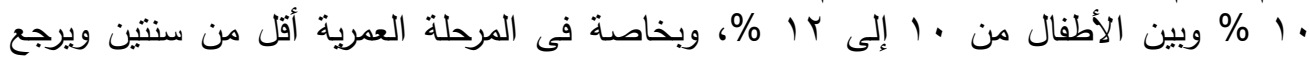
السبب فى ذلك للتزايد المستمر فى معدلات التلوث والتئ التدخين واستعمال المبيدات.

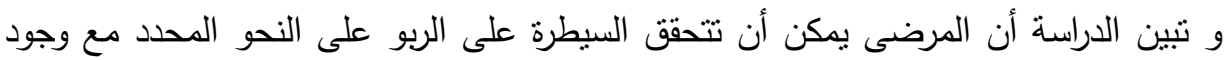

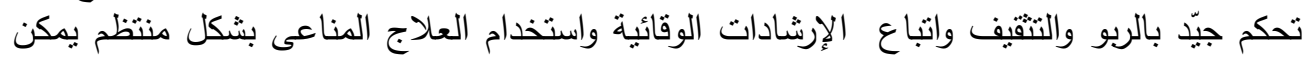
للأطفال وللكبار المصابين بالربو عيش حياة طبيعية ونشطة.

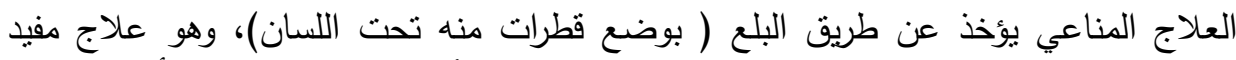

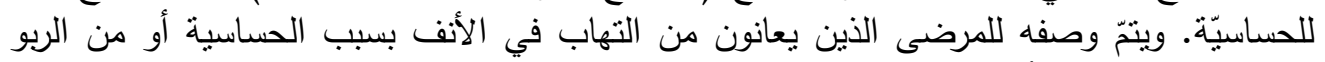

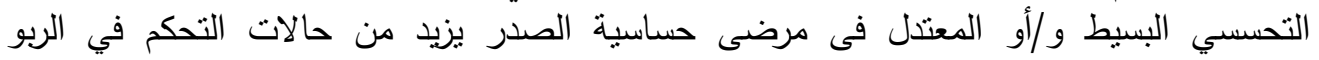

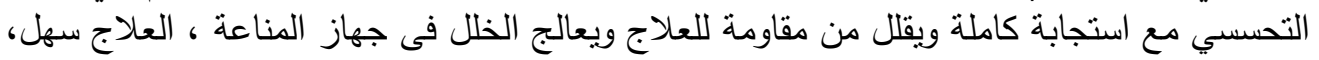

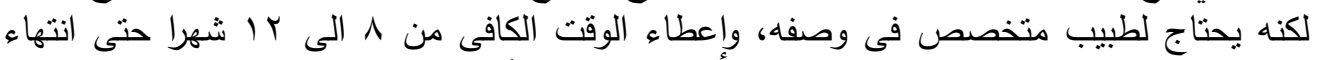
الفترة العلاجية للعلاج المناعي. خلصت نتائج الدراسة إلى أن العلاج المناعى المنتظم مع العلاج 
Journal of Environmental Sciences (JES)

Faculty of Graduate Studies and Environmental Research, Ain Shams University

Osman, et al.

الدوائي والعلاج الوقائي البيئي علاج امن الى حد بعيد وفعال أدى إلى انخفاض كبير في أعراض الربو وتحسين وظائف التتفس ، وكذلك تحسين السيطرة على الربو .

Vol.(50); Iss.(8); No.(5); Aug. 2021

ISSN 1110-0826

Online ISSN 2636-3178 